\title{
Cultura jovem e identidade: as representações do funk carioca em Londres
}

Jamile Dalpiaz

Mestre em Mídia, Comunicaşão e Estudos Culturais pelas universidades de Florença (Dispo)

e Londres (Institute of Education), na Inglaterra, e em Comunicaşão e Informação pela

Universidade Federal do Rio Grande do Sul (PPGCOM/UFRGS).

E-mail: jadalpiaz@hotmail.com

Resumo: Este artigo estuda o funk carioca sendo promovido em Londres e analisa as representações que envolvem não apenas a cultura jovem e a música popular, mas também questões sociais de classe, raça e gênero. Para tanto, o documentário Sou feia, mas tô na moda é tomado como objeto de análise. $O$ texto divide-se em duas partes. A primeira trata do significado do funk nas favelas cariocas, explorando as características da cultura jovem, da música e da identidade local. A segunda identifica as representações do funk no documentário em relação ao contexto cinematográfico brasileiro e reflete sobre esta produção a partir da teoria multimodal.

Palavras-chave: Música, cinema, cultura jovem, identidade, representação.
Abstract: This research focuses on Brazilian funk being promoted in London. The main aim is to analyze the phenomenon of funk music created in the slum context in Rio de Janeiro and to identify how it has been represented in UK. To better illustrate this theme, this essay's focus is the documentary I'm ugly but trendy. This study is divided into sections. The first reading is concerned with the significance of funk in Rio's slums, by exploring the relationship between youth slum people, funk music and local identity. The second is concerned with the representations of funk carioca displayed through the film. The video has been selected as a multimodal text.

Keywords: Music, cinema, youth culture, identity, representation.

Há uma presença contínua de representações da cultura brasileira na cobertura jornalística e no meio publicitário internacional, nos quais o futebol, o carnaval e a desigualdade social são pautas de rotina. Com relação à música não é diferente: samba, bossa-nova, axé são estilos difundidos em emissoras de rádio e discotecas da Europa. Este artigo, no entanto, estuda o funk carioca sendo exibido em Londres (Inglaterra), analisando representações que envolvem a cultura jovem e a música popular. Este fenômeno salienta a emergência de espaços onde o local e global apresentam-se interligados. A escolha deste tema deve-se a uma experiência de pesquisa na capital inglesa, que viabilizou um contato com a mídia local e diferentes manifestações culturais brasileiras. 
comunicação \& educação • Ano XVI • número 1 • jan/jun 2011

1. A discoteca Guanabara tem como proposta apresentar no West End músicos, DJs e novidades da música brasileira. Disponível em: <http://www. guanabara.co.uk>.

2. $A$ rádio $B B C$ veicula programas de funk carioca, assim como o grupo de brasileiros da Tetine Band produz, às terças-feiras, o programa Slum Dunk, na rádio Resonance FM londrina.

3. SOU FEIA, mas tô na moda. Direção de Denise Garcia. Longa-metragem documentário. $61 \mathrm{~min}$ Vídeo Digital. Brasil, 2004-2005.

4. A versão em inglês, para exibições no exterior, não foi disponibilizada para esta pesquisa. As imagens analisadas neste estudo foram ex traídas do vídeo trailer, disponível em: <http:// www.youtube.com/ watch?v=PdQerRxh|Dc $>$ Acesso em: 12 set. 2010.
Foram identificadas matérias sobre o funk carioca e sua introdução no contexto inglês; promoções deste estilo musical em discotecas ${ }^{1}$ e emissoras de rádio; ${ }^{2}$ além de exibições de documentário brasileiro sobre o funk. Estariam os ingleses compreendendo aquilo que estavam ouvindo ou assistindo? Estas representações de fato traduzem o contexto social dessas comunidades? Qual seria o efeito dessas representações sob o consumo desse tipo de música na Inglaterra? Diante disso, constatou-se a necessidade de ilustrar de que modo tais representações envolviam não somente a cultura jovem e a música, mas também questões de classe, raça e gênero presente nas imagens e nos textos das músicas veiculadas. A evidência do fenômeno resultou em problematizações quanto às práticas dos ingleses: compreensão das letras e da realidade traduzida no filme.

Portanto, o objetivo desta pesquisa é analisar o fenômeno da música funk criado no contexto das favelas do Rio de Janeiro a partir das representações exibidas em Londres. Este objeto será estudado sob o olhar das teorias da cultura no contexto globalizado das expressões da juventude. No entanto, após uma reflexão sobre o material, percebeu-se, pela complexidade do tema, a necessidade de delimitar o estudo. Desse modo, a análise se concentra no documentário Sou feia, mas tô na moda ('’m ugly but trendy), de Denise Garcia $^{3}$, que narra a história de jovens cantoras de funk enquanto mulheres, esposas, estudantes e trabalhadoras. O documentário foi apresentado pela primeira vez no festival Slum Dunk Music Film Programme, em Londres, em março de 2005, seis meses antes do lançamento oficial no Brasil, o qual ocorreu no Festival (de Cinema) do Rio, no mesmo ano ${ }^{4}$.

$\mathrm{O}$ presente artigo está dividido em duas partes. A primeira trata do significado do funk nas favelas do Rio, trazendo estudos que

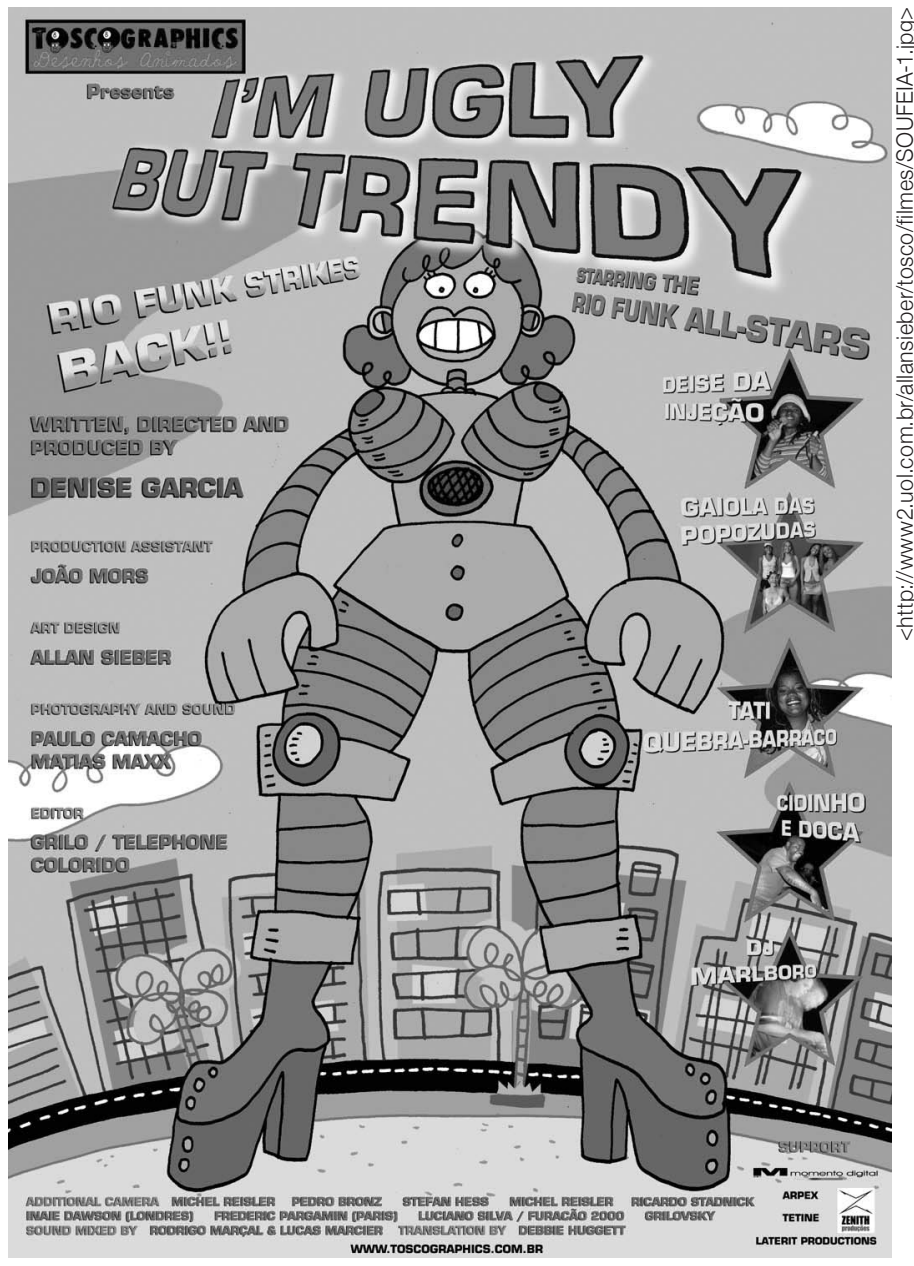

Cartaz internacional do filme. 
exploram a relação dos jovens com o funk e a identidade local. A segunda realiza uma leitura das representações do funk carioca no documentário como texto multimoda $\tilde{b}$, a partir das categorias: discurso, design, produção e distribuição. A cobertura da mídia e a entrevista com a diretora Denise Garcia ${ }^{6}$ também são contempladas.

\section{APROXIMAÇÃO TEÓRICA}

Esta pesquisa apoia-se nos conceitos de identidade cultural e representação com o objetivo de verificar como se manifestam no filme. A identidade cultural é aplicada no sentido que Hall dá ao termo:

Ponto de sutura entre, de um lado, os discursos e as práticas que nos interpelam enquanto sujeitos sociais de um determinado lugar e, de outro, de processos de produção de subjetividade, os quais nos constituem enquanto sujeitos. Identidades são estes pontos temporários de apego a posicionamentos enquanto sujeitos nos quais as práticas discursivas são construídas para e por nós ${ }^{7}$.

Esta perspectiva é norteadora para explorar a identidade jovem da favela em torno do funk, no sentido em que está formada, considerando o contexto socioeconômico no qual está inserida.

A representação é outra definição de Hall descrita como parte essencial do processo de construção de sentido, produzido e intercambiado por membros de uma cultura:

[...] é a produção de sentido e de conceitos nas nossas mentes por meio da linguagem. É a conexão entre os conceitos e a linguagem, que nos permite fazer referimento ao mundo "real" ou "imaginário" dos objetos, pessoas e eventos ${ }^{8}$.

A mídia está constantemente produzindo representações do mundo real visando dar sentido às mesmas em outros contextos e públicos. As imagens e as reproduções de mensagens produzidas $d a$ e sobre as identidades das favelas cariocas são representações deste universo.

A globalização ${ }^{9}$, a velocidade e a compressão de espaços permitiram uma integração de diferentes contextos e identidades. As representações das identidades das favelas cariocas exibidas na capital inglesa são exemplos desse processo. Bennett ${ }^{10}$, por seu turno, analisou as relações entre a música popular, a cultura jovem, o lugar e a identidade. Este autor realizou estudos etnográficos sobre o uso coletivo da música popular por jovens em lugares específicos $^{11}$, que evidenciam o interesse sociológico pelo local enquanto espaço no qual as culturas juvenis operam e grupos compartilham uma estrutura cultural de referência, em termos de conhecimento coletivo e de suas sensibilidades. Resulta deste a evidência de se relacionar o significado do conteúdo musical ao contexto cotidiano da subcultura ${ }^{12}$, no qual a música é ouvida coletivamente. Portanto, acredita-se que, por meio de uma análise das características do documentário e do processo de promoção em Londres, será possível identificar elementos que constroem uma relação entre o universo carioca e londrino.
5. KRESS, G.; VAN LEEUWEN, T. Multimodal discourse. The modes and media of contemporary communication (Discurso multimodal: os modos e meios de comunicação contemporânea). London: Hodder Arnold, 2001.

6. A diretora do documentário, Denise Garcia, concedeu entrevista à autora e à pesquisadora Liv Sovik, em 26 de junho de 2007, em Londres.

7. HALL, S. Who needs identity? (Quem precisa de identidade?). In: DU GAY, P.; EVANS, J.; REDMAN, P. Identity: a reader (Identidade: um leitor). London: Sage, 2000. p. 19.

8. HALL, S. Representation: cultural representations and signifying practices (Representação: representações culturais e práticas significantes). London: Sage, 1997. p. 17.

9. HARVEY, D. The condition of Post modernity. An inquiry into the Origins of Cultural Change (A condição pós-moderna: uma pesquisa sobre as origens da mudança cultural). London: Cambridge University Press, 1980.

10. BENNETT, A. Popular music and youth culture. Music, identity and place (Música popular e cultura jovem: música, identidade e lugar). New York: Palgrave, 2000.

11. Bennett (2000, p. 17) descreve a história da cultura juvenil enquanto objeto de estudo da sociologia.

12. Sobre subcultura, ver HEBDIGE, D. Subculture. The Meaning of Style (Subcultura: o significado do estilo). London: Methuen, 1979. 
13. VALLADARES, L. A gênese da favela carioca: a produção anterior às ciências sociais. Revista Brasileira de Ciência Sociais, v. 15, n. $44, p$. $5-34,2000$

14. HERSCHMANN,M Demonização e glamorização na mídia. Disponível em: <http://www. multirio.rj.gov.br/secu lo21/pdf/demonizacao_e glamourizacao_na_midia. pdf $>$. Acesso em: 28 jun. 2007; e JAGUARI$B E, B$. Favelas and the aesthetics of realism representations in film and literature (Favelas e a estética do realismo: representações nos filmes e na literatura). Disponíve em: <http://www.pos. eco.ufrj.br/disciplinas/file. $\mathrm{php} / 58 / \mathrm{minh} a \mathrm{~s}$ publicacoes/bjaguaribe1.pdf $>$. Acesso em: 28 jun. 2007.

15. VIANNA, H. O mundo funk carioca. Rio de Janeiro: Zahar, 1988.

16. Id. Funk e cultura popular carioca. Estudos Históricos, Rio de Janeiro, v. 3, n. 6, p. 244-253 1990.

17. HERSCHMANN, M Demonização e glamourização na mídia. Disponível em: <http://www. multirio.rj.gov.br/secuo21/pdf/demonizacao_e glamourizacao_na_midia. pdf $>$. Acesso em: 28 jun. 2007. comunicação \& educação • Ano XVI • número 1 • jan/jun 2011

\section{O FUNK NO RIO DE JANEIRO}

O funk carioca surgiu quando jovens moradores dos subúrbios começaram a compor canções a partir de músicas americanas de hip-hop, tocadas em clubes e festas por Disc Jockeys (DJs) locais. Trata-se de uma reelaboração dos grupos das favelas. No entanto, há familiaridades quanto ao conteúdo das letras: violência urbana, sexo, desigualdade social e racial, elementos do contexto suburbano. No Rio, as cantoras começaram a promover versões sem usar o rap (canto improvisado). Inicialmente, participavam como dançarinas, em seguida, tornaram-se Mestres de Cerimônia (MCs), ganhando notoriedade ao exibirem versões que narram histórias sobre sexo casual e o cotidiano das favelas ${ }^{13}$. Nos últimos anos, este fenômeno musical se espalhou por outras classes sociais. Os espaços de sociabilidade são os bailes funks onde as MCs passam horas fazendo performances para uma audiência de milhares de pessoas.

Existe uma diversidade de pesquisas sobre desigualdade social no Brasil; no entanto, busca-se referir neste artigo estudos sobre representações das favelas e do funk carioca na mídia ${ }^{14}$. Contudo, vale reconhecer que, já na década de 1980, o antropólogo Hermano Vianna ${ }^{15}$ desenvolveu pesquisa etnográfica sobre os bailes funk explorando o universo suburbano até então desconhecido do Rio. Sua contribuição descreve a introdução do funk nessas comunidades, nos anos 1970, e o envolvimento expansivo de público negligenciado pelas classes sociais mais favorecidas e pela mídia. No final dos anos 1980, cerca de 700 bailes funks aconteciam semanalmente no Rio de Janeiro. Cada um reunia, pelo menos, mil pessoas, sendo que alguns concentravam de seis a dez mil pessoas. O fenômeno ainda persiste. De acordo com Denise Garcia, são cerca de 500 bailes por semana, que reúnem mais de cinco mil pessoas cada. Se, no início, a mídia parecia ignorar a existência do lado carente carioca, hoje é representado pelos meios como a violenta e exótica face do país. Vianna ${ }^{16}$ aponta ainda que o funk carioca não sofreu imposições da indústria cultural norte-americana. As gravadoras refutaram - por muito tempo - o mercado brasileiro. Os jovens dos subúrbios apreciavam o funk, mas encontravam dificuldades em adquirir álbuns. No início, eram apenas os DJs a promoverem o funk através dos bailes. Os grupos mais conhecidos eram: Furacão 2000 e Soul Grand Prix. Há também um protagonista nessa trajetória, o DJ Marlboro, responsável pela nacionalização do funk nas rádios locais e pela promoção de bailes.

Estudos recentes demonstram que o fenômeno suburbano do Rio não foi notícia até a década de 1990, assim como não participou da sociabilidade das classes médias cariocas até recentemente. Micael Herschmann ${ }^{17}$ comprova este paradoxo em sua análise de reportagens publicadas na imprensa sobre o funk. De um lado, observou que havia o funk identificado com a criminalidade e a violência no contexto carioca. De outro, que a música funk começava a ser reconhecida como expressão cultural e representação de um segmento particular. Isso explica o interesse de outras audiências, incluindo a londrina. É importante salientar, no entanto, que os elementos relacionados ao funk carioca e à cultura jovem da favela estão presentes na promoção e no consumo 
dos bailes funk. Thornton (1995) contribui na compreensão da relação entre espaço e cultura:

A cultura de clubes é a cultura do gosto. As massas que frequentam clubes geralmente congregam na sua base o gosto pela música [...]. A participação na cultura de clubes constrói afinidades, sociabiliza os participantes no conhecimento daquilo que gostam ou desgostam (frequentemente em beneficio de), significados e valores culturais ${ }^{18}$.

Contudo, o estilo musical é o elemento principal desta comunicação. Quando o funk norte-americano começou a ser difundido nos subúrbios cariocas, as comunidades jovens não compreendiam o significado das letras das músicas. Atualmente, o público de Londres - ou de outros países onde é exibido - dificilmente chegam a compreender o conteúdo linguístico. No entanto, o estilo musical está presente, convidando audiências a aprenderem mais sobre este específico contexto.

Se no início o funk concentrava-se nos bailes, logo surgiu um novo elemento: a mulher, que conquistou espaço e passou a invocar discursos de gênero. No passado, o papel das mulheres era apenas o de dançarinas eróticas. Hoje as jovens adquiriram visibilidade: são cantoras exibindo ideias, sentimentos, discursos do cotidiano, liberdade sexual e poder na estrutura socioeconômica familiar. Mais ainda, o funk vem estimulando as jovens a deixarem o trabalho diário - de domésticas ou cozinheiras - para perseguirem a fama como MCs, como demonstra o filme em questão ${ }^{19}$.

\section{REPRESENTAÇÕES DO FUNK CARIOCA NO DOCUMENTÁRIO}

É oportuno destacar aspectos do universo das favelas e do período em que o filme Sou feia, mas tô na moda foi produzido. O estudo de Jaguaribe ${ }^{20}$ demonstra a relação contraditória existente entre a favela e a cidade no contexto brasileiro. Conforme aponta, o acesso às mercadorias e serviços é determinado pelas relações econômicas cujas proporções de distribuição de renda nestas comunidades são adversas. A produção de representações sobre as favelas tem sido utilizada como outra forma de realismo estético, apresentando narrativas e imagens da fragmentada identidade brasileira. A produção cinematográfica brasileira, desde a década de 1990, tem buscado representar as identidades brasileiras enfocando personagens marginalizados, comunidades carentes, cultura das drogas, violência e migração. Consequentemente, as audiências encontram uma composição de realismo e autorreferência em temas relacionados ao contexto nacional ${ }^{21}$. Isto explica as produções - Cidade de Deus, Carandiru, Central do Brasil, entre outras -, que capturaram grandes audiências ao explorar elementos da realidade brasileira. Sou feia, mas tô na moda possui, portanto, a mesma função cinematográfica. Desse modo, é possível afirmar que estes documentários e ficções, quando exibidos no exterior, podem também ser interpretados como textos de vanguarda.
18. THORNTON, S. Club cultures. Music, Media and Subcultural capital (Cultura dos clubes: música, mídia e capital subcultural). Cambridge: Polity, 1995. p. 3.

19. RUDE revolution rocks Rio. Funk carioca with four-letter lyrics is the new dance craze sweeping Brazil (Revolução selvagem sacode o Rio: funk carioca com versos de quatro letras é a nova mania de dança que arrebata o Brasil). The Times. Disponível em: <http:// www.timesonline.co.uk/ article/0, 3-1634684,00. $\mathrm{html}$. Acesso em: 31 maio 2005.

20. JAGUARIBE, op. cit.

21. XAVIER, I. Brazilian Cinema in the 1990s: the unexpected encounter and the resentful character (Cinema Brasileiro nos anos 90: o encontro inesperado e o personagem rancoroso). In: NAGIB, L. The new Brazilian Cinema $(O$ novo cinema brasileiro). London: I. B. Tauris, 2006. p. 40. 
Sou feia, mas tô na moda trata do funk nas favelas do Rio sob o ponto de vista das cantoras, que também são mães, esposas e trabalhadoras. Hoje a presença das mulheres como MCs nos bailes funk é essencial. No entanto, vários profissionais estão envolvidos na produção dos bailes: equipes de som e iluminação, agentes, $D J s$, proprietários e empregados de clubes, vendedores ambulantes, entre outros. Pode-se afirmar que os bailes se tornaram um negócio lucrativo para a população dos subúrbios. O título do documentário origina-se de uma canção da MC Tati Quebra-Barraco, que trabalhava de cozinheira em creches antes de fazer shows de funk. Passou a receber por noite uma quantia equivalente a um mês de salário.

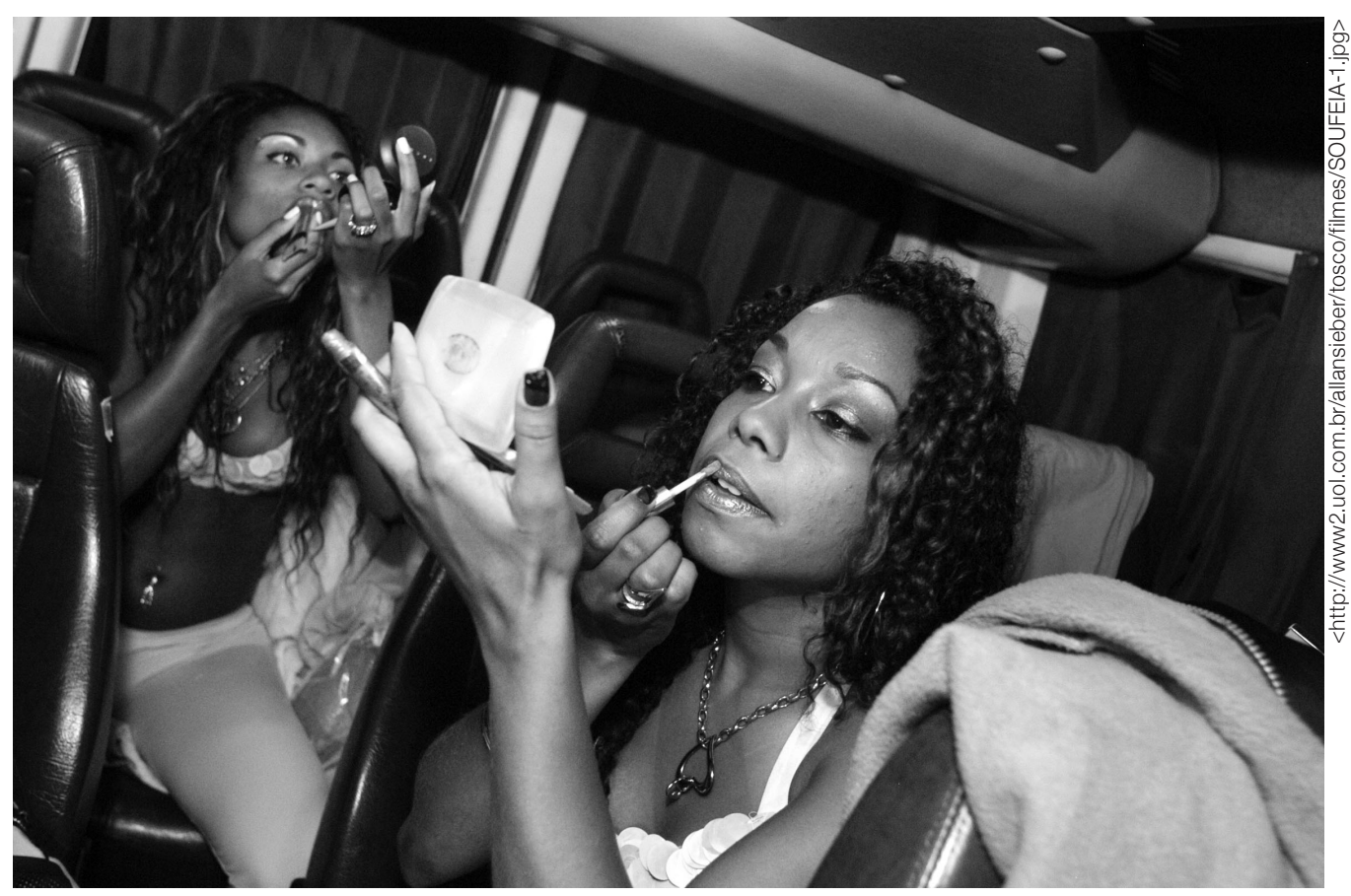

Jovens adquiriram visibilidade: são cantoras exibindo ideias, sentimentos, discursos do cotidiano, liberdade sexual e poder na estrutura socioeconômica familiar.

Segundo a diretora Denise Garcia, a ideia nasceu do desejo de explorar a realidade dessas mulheres:

A situação do funk nas favelas é a mesma do movimento punk, quando se iniciou em Nova Iorque e Londres. Precisavam falar, mas não sabiam como; utilizaram a música e o discurso ganhou voz. Tocavam rápido para expor fúria. Quando mudei para o Rio, esperava encontrar uma cidade de classes sociais misturadas. No Rio, os negros trabalham para os brancos se divertirem. De um lado, observava as mulheres de classe média com comportamentos moralistas. De outro, percebia jovens de comunidades se expressando com o funk de modo diferente. Elas estão na vanguarda em termos de discurso ${ }^{22}$.

Estas características serão problematizadas a seguir a partir de pistas encontradas na teoria discursiva multimoda $\ell^{23}$, a qual viabiliza uma análise de elementos relacionados ao significado de um texto midiático a partir de quatro 
categorias: discurso, design, produção e distribuição. Esta perspectiva se ocupa em interpretar como os textos constroem significados a partir das formas comunicativas, tais como a linguagem, a imagem, os sons e gestos, além de buscar integrar aspectos relativos às audiências ${ }^{24}$.

O vídeo inicia-se anunciando uma variedade de protagonistas e seus diferentes discursos: classe social, raça e gênero. São mostradas, em inglês, citações sobre a temática, que surgem na tela acompanhando o ritmo da música:

é som de preto, de favelado, mas quando toca, ninguém fica parado

intercaladas às imagens, que ilustram o conteúdo:

Mulheres desafiando os ideais da classe média (BlackFeminist.org).

Som revelador vindo do Brasil (The Times).

Feministas sem panfletos ou livro ( $O$ Globo).

E, ainda, depoimentos legendados:

Eles demoraram tempo pra caramba pra curtir o samba: aprenderam. Mas estão demorando muito mais pra curtir o funk (DJ de funk).

As representações, que tratam de liberdade sexual, também aparecem em declarações de protagonistas:

O funk, quando fala aquelas coisas depravadas, é o que está acontecendo mesmo (MC).

A música incentivou as mulheres colocarem pra fora (MC).

Falando assim, da mulher ficar de quatro, de lado (MC).

Realidade não é sacanagem, todo mundo gosta de fazer amor, de gozar gostoso (MC).

Esta música é feita com característica própria que lugar nenhum no mundo faz (DJ Marlboro).

Esses são extratos que demonstram reconhecimento desta identidade jovem, suburbana e musical. As cenas oferecem uma noção do design do documentário, mostram favelas, bailes funk e MCs em performances. Elas sugerem uma narrativa visual para o conteúdo e são dispostas na velocidade em que a música funk é exibida.

Garcia, sobre a produção, revelou as dificuldades enfrentadas na execução. Inicialmente foi a escolha do meio audiovisual, produção realizada com poucos recursos financeiros e tecnologia. Outro aspecto é a importância dos recursos humanos originais para gravações: os protagonistas do funk e a audiência envolvida, isto é, os jovens moradores das favelas. É possível identificar no documentário que a diretora buscou dar ênfase às diferentes personalidades do funk local. O vídeo apresenta DJs e MCs, além de depoimentos de pessoas de outros segmentos sobre o funk. Garcia salientou o valor de se compreender a linguagem do ambiente trabalhado. Ela acredita que seria difícil para um produtor estrangeiro realizar este tipo de documentário no Brasil sem dominar o idioma, fator crucial para se trabalhar com temas brasileiros. A distribuição do
24. BURN, A.; PARKER, $D$. Analysing media texts (Analisando textos midiáticos). London: Continuum, 2003. 
comunicação \& educação • Ano XVI • número 1 • jan/jun 2011

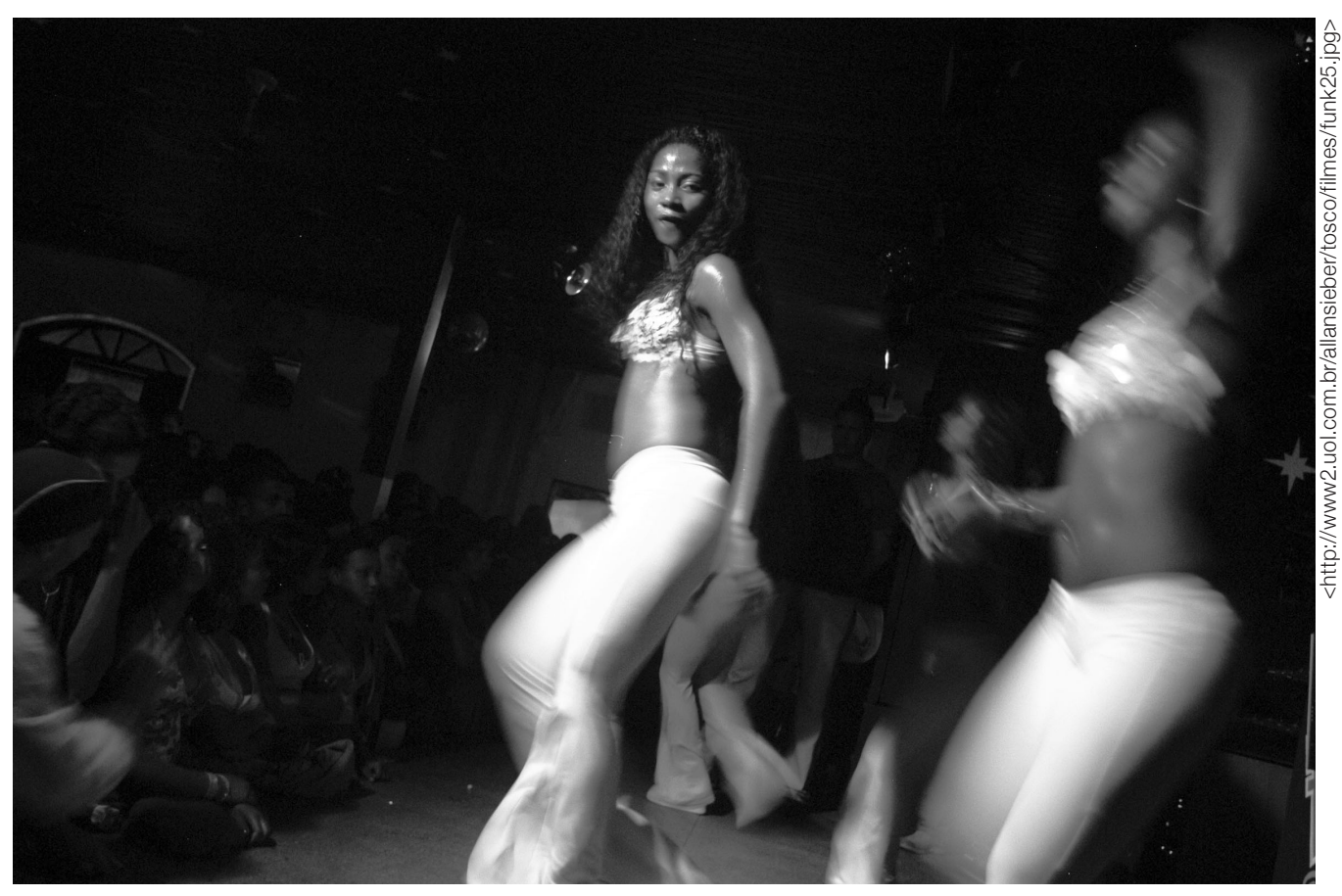

MCs prontas para apresentação.

filme buscou atingir a audiência brasileira e estrangeira. Garcia revelou que, antes de concluí-lo, empenhou-se em promovê-lo no exterior. O filme continua sendo discutido com propósitos culturais e de promoção. Em Londres, foi exibido em duas ocasiões: no lançamento, em 2005; e também na WhiteChapel Art Gallery, em exibição comentada com a participação da diretora, em junho de 2007. Outro importante aspecto foi o contrato assinado com a distribuidora Imovision. Os investimentos em tecnologia permitiram a conversão em alta qualidade de projeção e a distribuição em salas de cinema e em versões em DVD.

\section{CONSIDERAÇÕES FINAIS}

Esta pesquisa buscou ilustrar a versão do funk recriada por comunidades jovens da periferia carioca e representada em Sou feia, mas tô na moda. Ao explorar o tema, questões surgiram especialmente sobre a relação deste estilo musical com a cultura jovem, a identidade e o local de sociabilidade. O documentário traduz este fenômeno numa linguagem audiovisual a partir do papel da mulher no contexto das favelas. Além disso, foi possível constatar que o funk carioca pode ser estudado a partir de diferentes abordagens devido à complexidade: classe social, raça e gênero. Este estudo identificou a presença destes elementos, porém reconheceu a necessidade de serem analisados individualmente. Este artigo, porém, estudou o funk das favelas cariocas sendo representado em Londres. Nesse sentido, três constatações podem ser feitas. Uma delas constatou que o estilo musical é o principal elemento de ligação entre as audiências do Rio e de Londres. Esta relação está situada no fato de 
que o funk carioca é identificado com uma nova versão da música eletrônica de estilo funk. A segunda refere-se ao fato de que o documentário viabiliza outra possibilidade de leitura desse estilo, porque traduz o contexto e o apresenta a uma audiência externa, fora das comunidades originárias. O vídeo permite que a audiência se aproxime desta identidade jovem da periferia. A terceira está relacionada às identidades, isto é, o funk carioca é uma expressão da fragmentada identidade brasileira. Foi percebido ainda que, a fim de ser aceito como manifestação cultural no contexto interno, o elemento cultural deve ser introduzido no exterior antes de sua firmação no Brasil. Revela-se aqui um paradoxo: o funk obteve sucesso antes mesmo de ser vendido em discos ou CDs, em franca oposição ao processo normal de difusão de música da indústria fonográfica; no entanto, apenas ganhou notoriedade na mídia brasileira e, em outros contextos socioeconômicos, à medida que foi reconhecido fora do país como um texto de vanguarda promovido pela música.

\section{REFERÊNCIAS BIBLIOGRÁFICAS}

BENNETT, A. Popular music and youth culture. Music, identity and place (Música popular e cultura jovem: música, identidade e lugar). New York: Palgrave, 2000.

BURN, A.; PARKER, D. Analysing media texts (Analisando textos midiáticos). London: Continuum, 2003.

HALL. S. Who needs identity? (Quem precisa de identidade?). In: DU GAY, P.; EVANS, J.; REDMAN, P. Identity: a reader (Identidade: um leitor). London: Sage, 2000.

Representation: cultural representations and signifying practices (Representação: representações culturais e práticas significantes). London: Sage, 1997.

HARVEY, D. The condition of Post modernity. An inquiry into the Origins of Cultural Change (A condição pós-moderna: uma pesquisa sobre as origens da mudança cultural). London: Cambridge University Press, 1980.

HEBDIGE, D. Subculture. The Meaning of Style (Subcultura: o significado do estilo). London: Methuen, 1979.

KRESS, G.; VAN LEEUWEN, T. Multimodal discourse. The modes and media of contemporary communication (Discurso multimodal: os modos e meios de comunicação contemporânea). London: Hodder Arnold, 2001.

OSGERBY, B. Youth Media (Mídia da juventude). London: Routledge, 2005.

THORNTON, S. Club cultures. Music, Media and Subcultural capital (Cultura dos clubes: música, mídia e capital subcultural). Cambridge: Polity, 1995.

VALLADARES, L. A gênese da favela carioca: a produção anterior às ciências sociais. Revista Brasileira de Ciências Sociais, v. 15, n. 44, 2000. 
comunicação \& educação • Ano XVI • número 1 • jan/jun 2011

VIANNA, H. Funk e cultura popular carioca. Estudos Históricos, Rio de Janeiro, v. 3 , n. $6,1990$.

O mundo funk carioca. Rio de Janeiro: Zahar, 1988.

XAVIER, I. Brazilian Cinema in the 1990s: the unexpected encounter and the resentful character (Cinema brasileiro nos anos 90: o encontro inesperado e o personagem rancoroso). In: NAGIB, L. The new Brazilian Cinema (O novo cinema brasileiro). London: I. B. Tauris, 2006.

\section{Endereços eletrônicos}

HERSCHMANN, M. Demonização e glamorização na mídia. Disponível em: $<$ http://www.multirio.rj.gov.br/seculo21/pdf/demonizacao_e_glamourizacao_ na_midia.pdf $>$. Acesso em: 28 jun. 2007.

FILME sobre as mulheres do funk terá sua estreia mundial em Londres. Disponível em: <http://www1.folha.uol.com.br/folha/bbc/ult272u40483.shtml>. Acesso em: 11 mar. 2005.

JAGUARIBE, B. Favelas and the aesthetics of realism: representations in film and literature (Favelas e a estética do realismo: representações nos filmes e na literatura). Disponível em: <http://www.pos.eco.ufrj.br/disciplinas/file.php/58/ minhas_publicacoes/bjaguaribe1.pdf $>$. Acesso em: 28 jun. 2007.

LONDRES vai ganhar seu próprio Baile Funk. Disponível em:<http://www.bbc. co.uk/portuguese/cultura/story/2004/04/040330_funkebc.shtml $>$. Acesso em: 7 abr. 2004.

RUDE revolution rocks Rio. Funk carioca with four-letter lyrics is the new dance craze sweeping Brazil (Revolução selvagem sacode o Rio: funk carioca com versos de quatro letras é a nova mania de dança que arrebata o Brasil). The Times. Disponível em: <http://www.timesonline.co.uk/article/0,,3-1634684,00.html>. Acesso em: 31 maio 2005. 